Ciência e Natura, v. 37 Part 2 jun. 2015, p. 87-94

\title{
Microgrid optimal control using demand response programs
}

\author{
Farshad Akhgarzarandy
}

Department Of Electrical Engineering, Islamic Azad University, Shabestar, Iran

\begin{abstract}
This study, in order to address the issue of frequency and voltage regulation in a Microgrid tries. A central demand coupled with a comparative Tphnordy method is applied to a small Microgrid. All dynamical models in Simulink software / MATLAB simulation has been. Simulation results show that the proposed method is able to overcome the voltage changes, voltage Microgrid keep it stable.
\end{abstract}

Keyword: Microgrid, optimal control 


\section{Introduction}

Active participation of consumers in demand response (load needs of subscribers), by the USDOE as one of the key features of the smart grid as is. However, this can affect the balance between production and demand, and thus the system voltage and frequency of the desired hold. With the increased penetration of renewable energy, demand response can be effective. In a power system, increase or decrease, respectively increase and decrease the frequency of the primary indicators of the level of production. This change in frequency can be controlled through demand response $\{1\}$.

With the rapid increase in load demand and interest in the use of distributed generation (DG), the harder it is to control power systems. In isolated applications (isolated), the addition of a small or medium-sized DG to a distribution system may not have a significant impact on power quality in the feeder To cope with this challenge, a set of DG, bars and department stores as part of a distributed system independently and as a Microgrid management, the network can be connected to a network (home network) or island mode (separate from the main network) do $\{2\}$.

Controlling the frequency and voltage are known as ancillary services, has always been considered an essential part of a Power Systems to the required standards of quality they can be properly implemented.

Three different levels of frequency control (primary control, secondary and tertiary) in services is applied. In this way, reserves battalion and Ghyrgrdan (ie, production, storage, and responsive load) has a primary role in controlling the frequency of the short period of time between 30 seconds to 15 minutes.

Usually on the side of trendy stable only under very difficult times because once Zyrfrkansy separation is controlled. However, in the smart grid environment and by having more, some subscribers with the ability to store energy loads such as electric water heaters $(\mathrm{EWH})$ excellent candidates to contribute to the balance between production and demand are $\{3\}$. In networked mode (translation: when the original network is connected Microgrid), frequency and voltage as the original network, subnet, and adjust the frequency and voltage such that the previously mentioned result, through conventional ancillary services. However, adjusting the voltage and frequency should be independently verified Microgridha island state, especially in the absence of conventional ancillary services (eg, reserves battalion and Ghyrgrdan). Frequency and voltage regulation, and other power quality issues are the most important sources of renewable energy, distributed generation Microgrid also be present. [4]

Tphnordy comparative method (AHC) is used to set the frequency for responsive handling. By changing the frequency, level of responsive loads (assuming there is an electric water heater) must at all times act in an optimal frequency, are determined to maintain. Simulation results show that the proposed method can effectively improve the steadystate and transient voltage and frequency variations.

\section{Describe the system}

To prove this concept, this study considered a small Microgrid. It includes a diesel Microgrid $3.125 \mathrm{MW}, 2.4 \mathrm{kV}$ to a speed governor and a Aksaytr (stimulus) as a DG equipped and also has loads (Responder) is fixed and dynamic active. The system configuration is shown in Figure 1. In general, a storage device is part of Microgrid, however, since the goal of this project is to Tphnvrdy adaptive capacity (AHC) for stabilizing frequency and voltage displays, storage devices are not considered in simulation studies and not shown in Figure 1. 


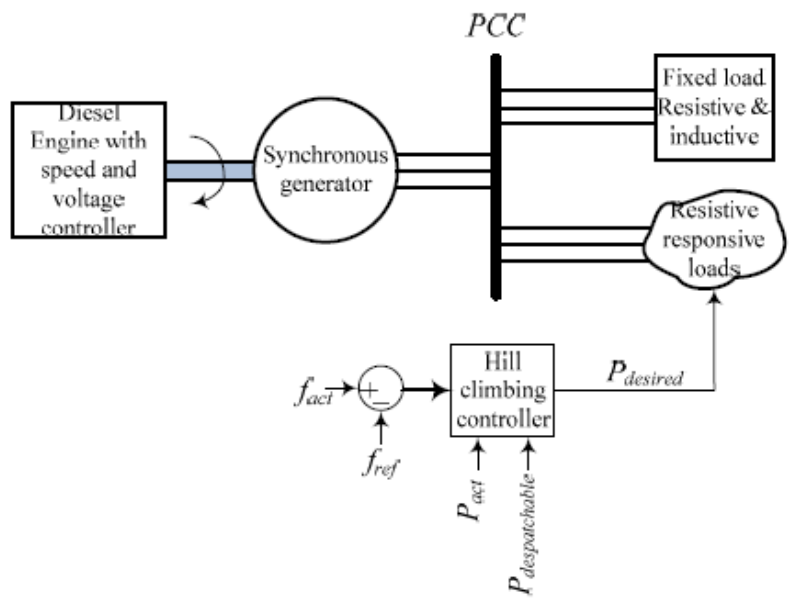

Figure 1. System configuration are presented.

It also will be used to validate the effective voltage, which will be shown in Section IV. This is because the generator output voltage depends on the power demand of the generator. Therefore, to meet the real-time control of both the frequency and the output voltage to be adjusted Microgrid simultaneously.

This study is used to validate the frequency distribution level, where Microgridha usually operate at this level, focused on the regulation of resistive loads. To adjust the frequency with resistive load control system, control of AHC (described in Section III) is usedo. Resistive load equal to $15 \%$ of the time is considered, ie $15 \%$ of the total load to be controlled. Each time the answer is supposed to be a $4.5 \mathrm{~kW}$ electric heater, which can be turned on or off state is $\{5\}$. Dynamic model diesel engine with a governor and controller of synchronous generator excitation and Simulink SimPowerSystems toolbox /matlab mining, which is based on 421.5 IEEE standard. Dynamic load, as seen in Figure 2 is modeled in dq frame. According to the theory, dq, the direct axis and perpendicular (id and iq) can be stated as follows:

$$
\begin{aligned}
& i_{d}=\frac{2}{3} \cdot \frac{v_{d}}{v_{d}^{2}+v_{q}^{2}} \cdot P+\frac{2}{3} \cdot \frac{v_{q}}{v_{d}^{2}+v_{q}^{2}} \cdot Q \\
& i_{q}=\frac{2}{3} \cdot \frac{v_{q}}{v_{d}^{2}+v_{q}^{2}} \cdot P-\frac{2}{3} \cdot \frac{v_{d}}{v_{d}^{2}+v_{q}^{2}} \cdot Q
\end{aligned}
$$

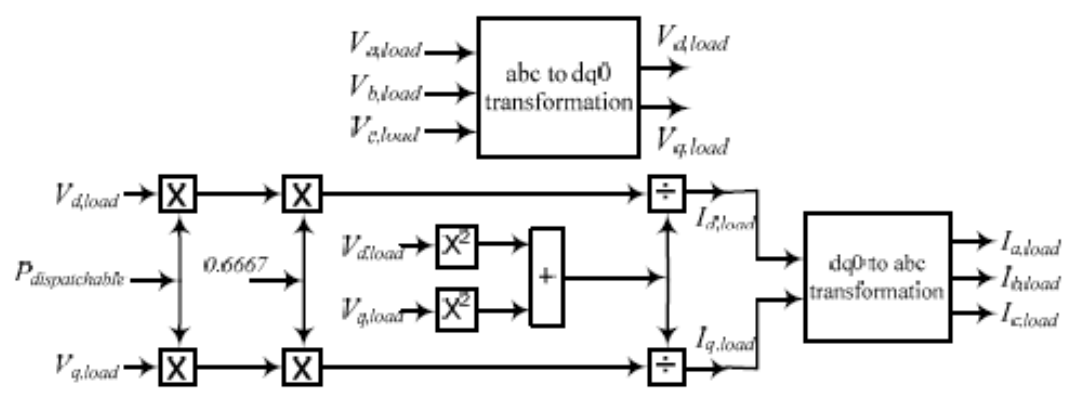

Fig 2. Dynamic modeling of active time.

In this case, $\mathrm{P}$ and $\mathrm{Q}$ are active and reactive powers Mtlbv resistive load, and vd, vq (id, iq) voltage (current) in the dq frame. To convert the values of abc frame to dq and, conversely, a Hlqhbsth phase (PLL) is used. Values of the voltage across the load voltage in $\mathrm{dq}$ frame are extracted. The $\mathrm{d}$ and $\mathrm{q}$ axes, which are calculated through the dq0 blocks abc, abc will be moved to the $\{6\}$. Proposed control strategy
Proposed control strategy, the control performance of EWH (boilers) of respondents, frequency Microgrid regulates the balance between demand and production at any point in time is established. On average, electricity consumption, household water heaters account for about $11 \%$ of total electricity consumption in peak hours and the amount of demand (load) is more than $30 \%$. Therefore, 
the electric water heater demand response applications in stabilization of voltage and frequency can be very helpful. When the frequency change, $\Delta \mathrm{f}$, is negative (due to low production and high demand), then the answer is working loads off (OFF) will. On the other hand, when $\Delta \mathrm{f}$ is positive, which is working to meet the loads are switched on (ON) will. Thus, the percentage of electric water heaters in the ON / OFF continuously adjusted, as shown in Figure 3, to keep the system frequency to an optimal level.

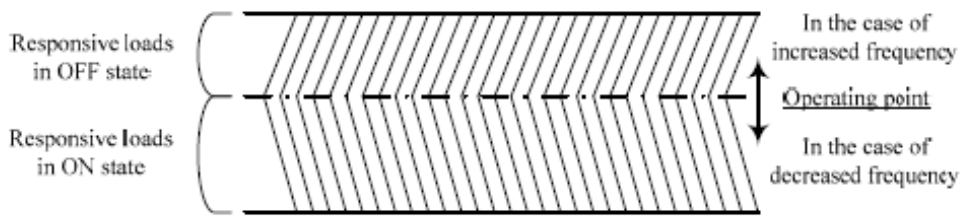

Fig 3. The idea of responsive load control

Tphnvrdy adaptive techniques (AHC) is applied to the percentage of time that should be held accountable for every moment of time is used for stabilizing frequency determined. This technique was first used to track the maximum power point (MPPT) of photovoltaic systems is introduced

Thus, the performance of PV systems due to sunlight and temperature changes corresponding to the maximum power will move. In this study, the technique used for frequency stabilization. This function is described in the flowchart in Figure 4. With the actual frequency, $\Delta \mathrm{f}$ can be calculated. If $\Delta \mathrm{f}$ is less than a predetermined threshold value, the system is placed in a secure place. Otherwise, the amount required to meet the load switch (or off) due to the frequency change signal is turned off (or on) will. This loop continues until the frequency is less than the threshold value.

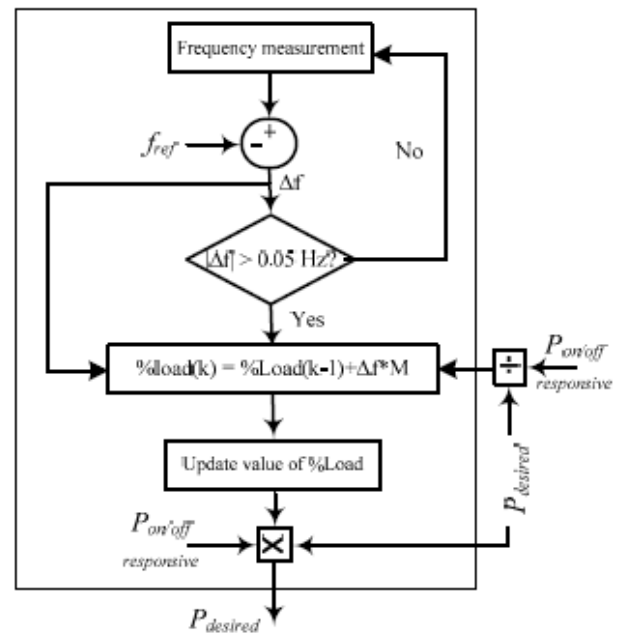

Figure 4. Flowchart Tphnvrdy adaptive techniques.
The original algorithm Tphnvrdy, a disorder parameter is defined as a fixed point performance with a new maximum power point move. It is shown that the choice of this parameter is in fact a compromise between improved dynamic response and steady state performance. The conclusion is that the ideal is that the parameters during the transient phase in steady state, large and small, will be provided. In this study, the parameters $M^{*} \Delta f$ is impaired, where $M$ is a constant used to reduce the scale of the difference frequency, such that the percentage of responsive loads required at each sampling point using the $\% \mathrm{k}$ on the previous ones (k-1 respectively) is, according to the flowchart in Figure 4. A larger value for $M$, resulting in improved dynamic performance, but at the same time, makes the control more responsive loads that may have an impact on the welfare of consumers to share. In this way, when the frequency difference is large, the step increase (or decrease) in the respondent's loads great. On the other hand, the incremental step load changes responsive to small frequency changes, some small. In this study, $\mathrm{M}=0.1$, which is neither too small nor too big. Algorithm used is updated once every 01/0 seconds. . Both delay control algorithm can be considered to be prevented from switching unnecessarily responsive handling. Since electric water heater loads are purely resistive, so it will be very rapid reaction to changes. Therefore, it can be assumed that their response to changes without delay. . In this study, a wireless network as communication 
protocol between the controlled entity and is often considered a delay (latency) is less than 20 milliseconds. As will be shown in Section IV, larger delays will cause more and longer until the meeting of the frequency response [8].

On the side of trendy maximum permissible frequency difference for a power system is about $\pm 0.2 \mathrm{~Hz}$, while for small power systems with low inertia, this amount could be larger. Great Britain's power system, this value is \pm $0.5 \mathrm{~Hz}$. Moreover, in the power of Great Britain, before the controller will respond to the signal frequency, $\pm 0.015 \mathrm{~Hz}$ frequency band died there. The value of the power system in North America is approximately \pm $0.01 \mathrm{~Hz}$. According to the flowchart in Figure 4 , in this study, the threshold frequency is assumed to be $60 \mathrm{~Hz} \pm 0.05 \mathrm{~Hz}$ or $\pm 0.083 \%$.

\section{Results of the simulation}

Simulation studies under various loading conditions were carried out to evaluate the performance of the proposed control strategy. In order to show the positive and negative changes in the frequency, mechanical power diesel engine was limited to a certain maximum and minimum values, so as to increase or decrease the frequency of the reference frequency $(60 \mathrm{~Hz})$ can be simulated.

\section{A. No Control}

Figures 5 and 6, respectively AHC controller frequency response in the absence of DG systems for light and heavy loads show. In this case, at time $\mathrm{t}=10 \mathrm{~s}$ of $1.6 \mathrm{MW}$ load level shown in Figures vary. In the case of light load, active loads ranging from 1.2 MW to 1.5 MW used. Because the production rate is greater than demand, the frequency of its nominal value $(60 \mathrm{~Hz})$ goes further. When the load is equal to $1.3 \mathrm{MW}$ or greater, the speed governor DG is effective in stabilizing frequency. However, when the load reaches the value of $1.2 \mathrm{MW}$ or less, DG speed governor can sustain frequency (Figure 5). The frequency response of the system at high load is shown in Figure 6. Speed governor for frequencies up to $3.2 \mathrm{MW}$ DG is able to sustain. For loads greater than this value, load 3.3 MW, the frequency can sustain the speed governor.

\section{B. Active Controller}

The results of the simulation show, the system performance is compared in two situations: when the AHC controller is activated when the controller is disabled. The results show that the controller is activated when the system performance under different load conditions improve. In all cases, it is assumed that meets loads ON / OFF is equal to $15 \%$ of the time.
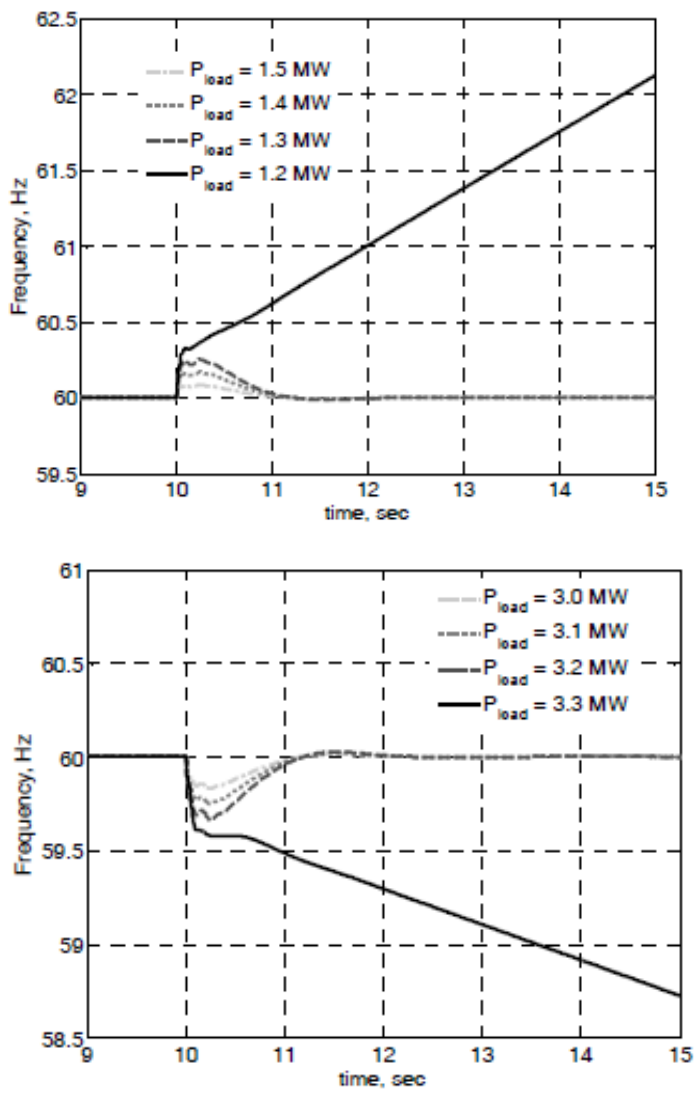

First: Upload Sbk- reduce the time

Figure 7 (a) $1.5 \mathrm{MW}$ load at time $\mathrm{t}=10$ seconds to load suddenly switch is $1.3 \mathrm{MW}$. Bound top and bottom bars have been named respondents in this format. 


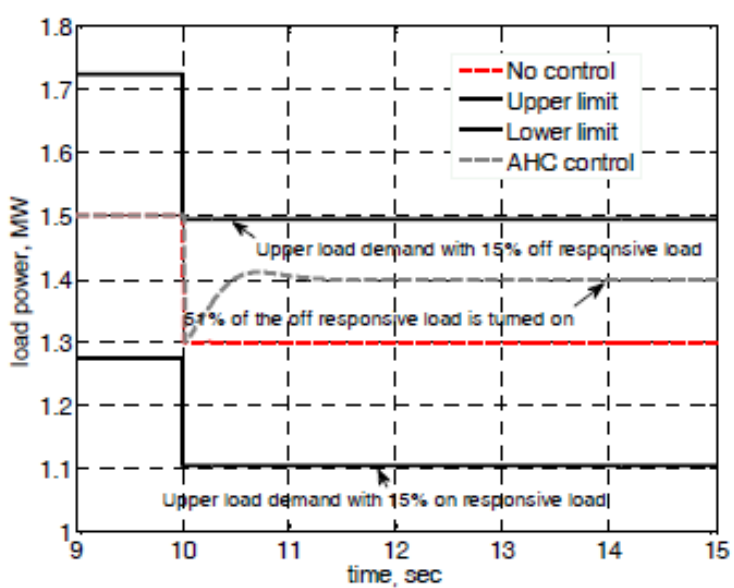

(a)
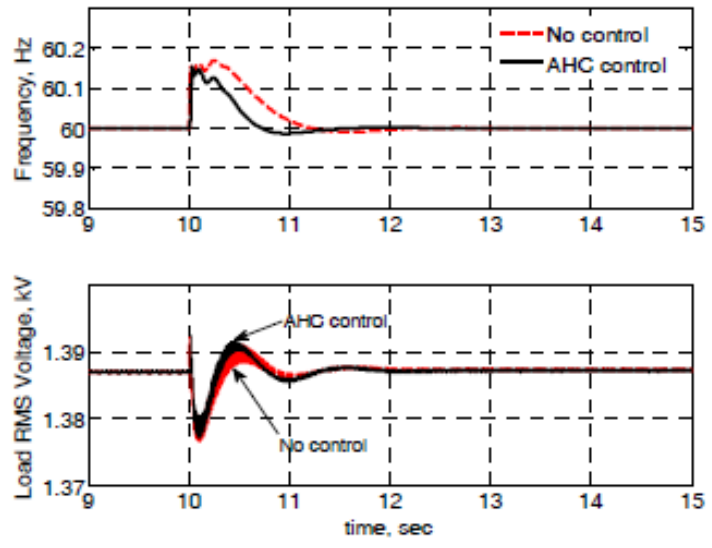

(b)

Figure 7. (a) be responsive load, (b) the frequency and voltage RMS value: Pload $=1.3$ MW.

As such, $51 \%$ of respondents loads gradually become clear by AHC (placed in orbit) to stabilize the frequency. Frequency and voltage profiles in Figure 7 (b) are displayed. From this figure, it is clear that the actions of the controller improves the transient behavior of the frequency response. It is also apparent that the volatility of output voltage transient activation of DG with AHC controller decreases.

Figure 8 shows the frequency response of the voltage generator in case of a sudden change in demand (load) of $1.5 \mathrm{MW}$ to $1.2 \mathrm{MW}$ at time $\mathrm{t}=10$ seconds. Figure 8 (a) shows the changing times, the upper and lower bounds to the load, responsive handling and response to frequency and voltage stabilization

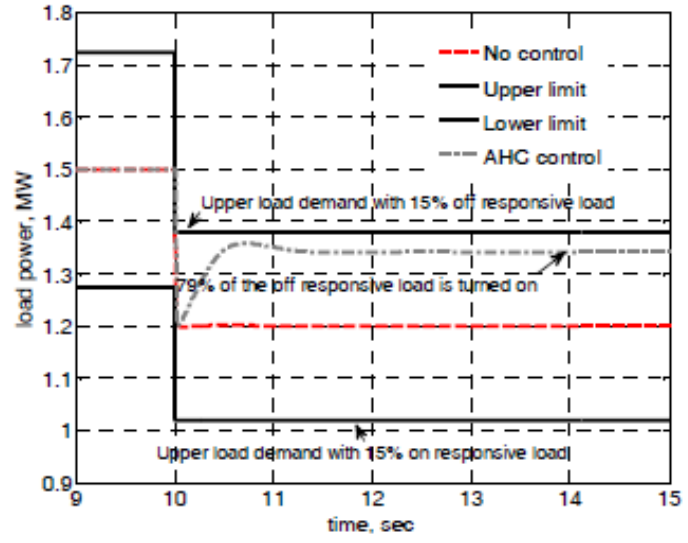

(a)
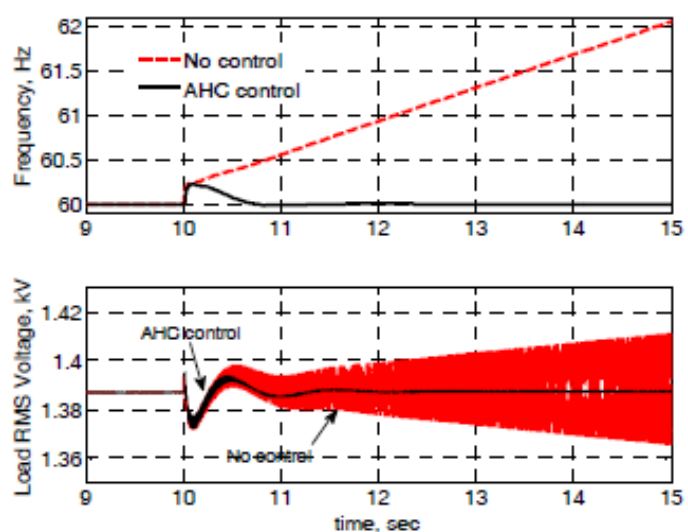

(b)

Figure 8. (a) be responsive load, (b) the frequency and voltage RMS value: Pload $=1.2$ MW.

Case 2: Upload Sngyn- increase in load In this case, the amount of 3.0 MW to 3.2 MW load suddenly increases, Figure 9 (a). Demand times for both control and AHC controller is shown in Fig. Be noted that in the steady state, $29 \%$ of respondents loads (formerly turned $\mathrm{ON})$, they are off to a frequency response as shown in Figure 9 (b) improve. In addition, AHC again when the controller is used, the voltage Ryplhay significantly destroyed and remain stable voltage.

Figure 10 (a), 3 MW load suddenly increases at a rate of 3.3 MW. Upper and lower limits to the load well responded by taking $15 \%$ of the time along with the controller load demand for both unchecked AHC, Given the is Continuing. $56 \%$ off loads of respondents had previously turned $\mathrm{ON}$, the system frequency remains within the standard. Figure 10 (b) shows the voltage and frequency profiles. AHC proposed controller, the frequency is stable, while the controller is not active, the 
frequency will exceed their limits. As in previous cases, the presence of AHC controller voltage is stable.

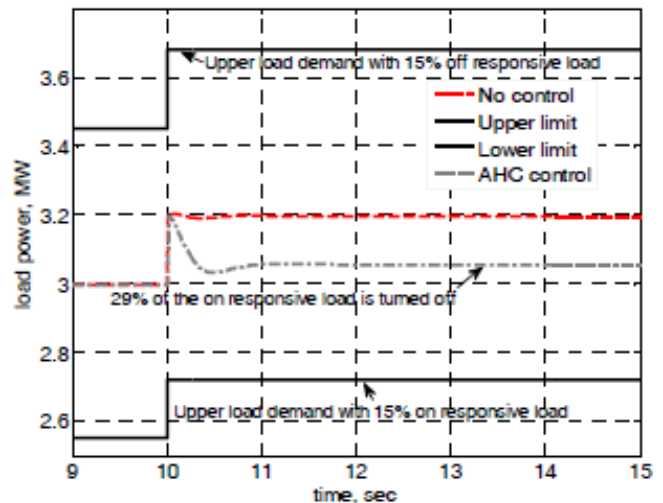

(a)
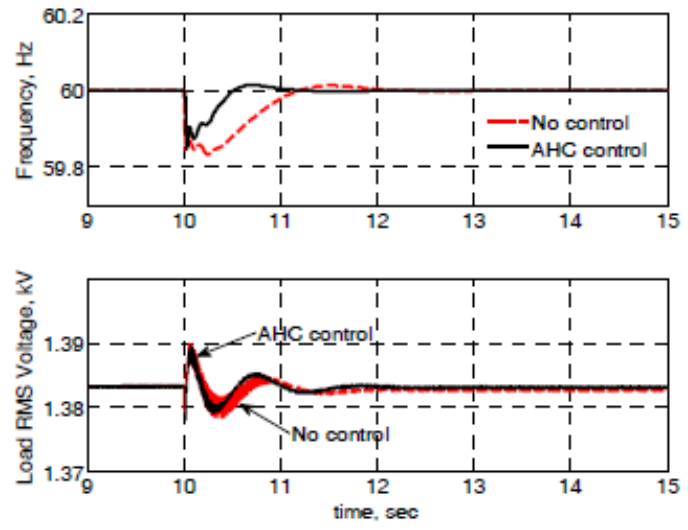

(b)

Figure 9

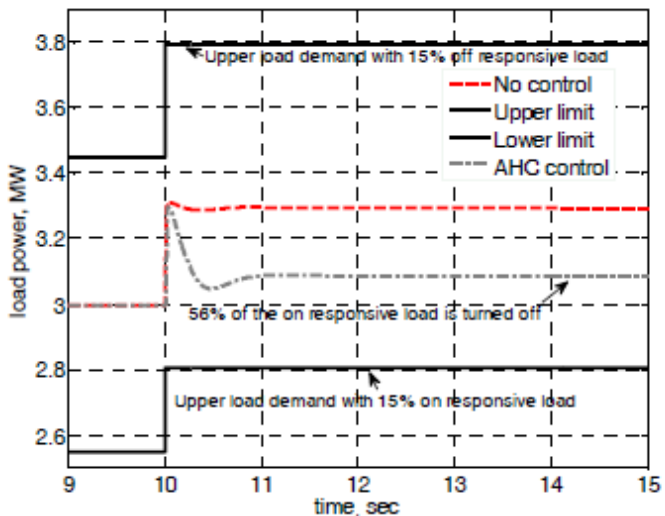

(a)
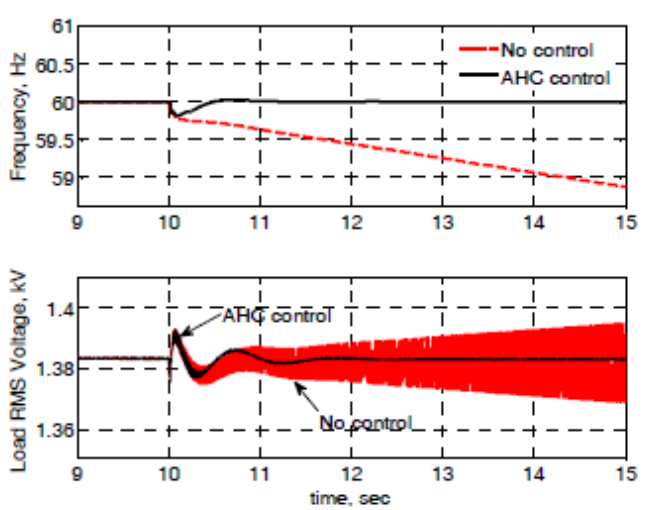

(b)

Figure 10

A. The effect of delay on the frequency response

Simulation results described above are all for the delay of $20 \mathrm{~ms}$. For further delays, it takes a long time to load responsive control commands received from the $\mathrm{AHC}$, and thus controls the frequency response will be delayed. Figure 11 Effect of long delays on the behavior of the transient frequency response under light load (1.3 MW) shows. From this figure, it is clear that for small delays, the transient period is very efficient machinery.

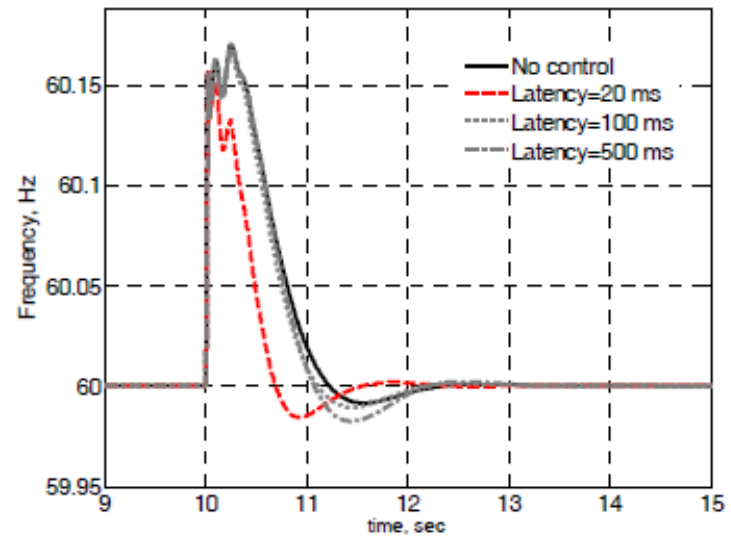

Figure 11

Figure 12 shows the simulation results corresponding to $1.2 \mathrm{MW}$ load. You can see that in terms of control, speed governor is capable of stabilizing the frequency, but the frequency of the controller is stable. However, when the delay increases, we are seeing more volatility in the frequency response. 


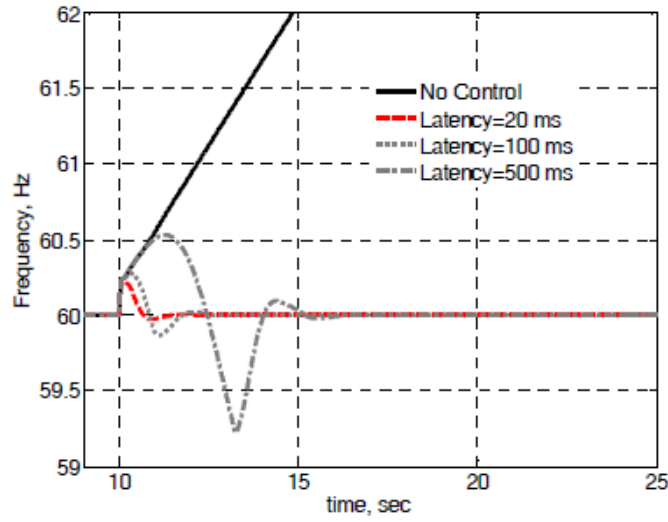

Figure 12

\section{Conclusion}

This project is for a Microgrid, a control strategy based on the frequency response using adaptive Tphnvrdy (AHC) was presented. Simulation results show that the response can be well applied in Microgrid to simultaneously adjust the frequency and voltage profiles and corrected. It was shown that the frequency of transient structures under sudden load disturbances improve. The proposed method is good for smart grid applications where load responsive control attained through a strong bilateral relationship.

\section{REFERENCES}

[1] A. Chowdhury and D. Koval, Power Distribution System Reliability: Practical Methods and Applications. Hoboken, NJ: Wiley-IEEE, Mar. 2009.

[2] B. Hussain, S. Sharkh, and S. Hussain, "Impact studies of distributed generation on power quality and protection setup of an existing distribution network," in Proc. Int. SPEEDAM, 2010, pp. 1243-1246.

[3] N. Nimpitiwan, G. T. Heydt, R. Ayyanar, and S. Suryanarayanan, "Fault current contribution from synchronous machine and inverter based distributed generators," IEEE Trans. Power Del., vol. 22, no. 1, pp. 634-641, Jan. 2007.

[4] H. Sharifian, H. Askarian Abyaneh, S. Salman, R. Mohammadi, and F. Razavi,
"Determination of the minimum break point set using expert system and genetic algorithm," IEEE Trans. Power Del., vol. 25, no. 3, pp. 1284-1295, Jul. 2010.

[5] Q. Yue, F. Lu, W. Yu, and J. Wang, "A novel algorithm to determine minimum break point set for optimum cooperation of directional protection relays in multiloop networks," IEEE Trans. Power Del., vol. 21, no. 3, pp. 1114-1119, Jul. 2006.

[6] P. Bedekar, S. Bhide, and V. Kale, "Optimum coordination of overcurrent relays in distribution system using dual simplex method," in Proc. 2nd ICETET, Dec. 2009, pp. 555-559.

[7] M. Mansour, S. Mekhamer, and N.-S. ElKharbawe, "A modified particle swarm optimizer for the coordination of directional overcurrent relays," IEEE Trans. Power Del., vol. 22, no. 3, pp. 1400-1410, Jul. 2007.

[8] P. Bedekar, S. Bhide, and V. Kale, "Optimum coordination of overcurrent relays in distribution system using genetic algorithm," in Proc. ICPS, 2009, pp. 1-6.

[9] P. P. Bedekar and S. R. Bhide, "Optimum coordination of directional overcurrent relays using the hybrid GA-NLP approach," IEEE Trans. Power Del., vol. 26, no. 1, pp. 109-119, Jan. 2011. 